\title{
Hypertension Persisted Following Bilateral Adrenal Medullectomy
}

\author{
Kyuzo Aoki, M.D., Kazuhiro Tazumi, M.D., Iwao SAto, M.D., \\ Yoshimi Kobayashi, Kiyoharu TakikaWa, M.D., \\ and Ken Hotta, M.D.
}

It was reported that spontaneously hypertensive rats (SHR) became normotensive following bilateral adrenalectomy (Aoki : Jap Heart J 4: 443, 1963). Hypertension was restored by the administration of adrenal cortical hormones in the adrenalectomized SHR (Aoki : Jap Heart J 4: 561, 1963; 5: 57, 1964). Recent biochemical observations indicated an increase in adrenal catecholamine content in SHR (Ozaki et al: Jap Circulat J 32 : $1364,1968)$. An increase in tyrosine hydroxylase and dopamine- $\beta$-hydroxylase activity in the adrenal medulla in SHR has also been reported (Nagatsu et al : Nature 230: 381, 1971). To clarify whether the adrenal cortex or medulla is primarily responsible for hypertension, blood pressure and adrenal catecholamine content was determined after adrenal medullectomy in SHR.

The mean systolic arterial blood pressure of the normotensive Wistar rat (NWR) was used as control $125 \pm 3$, and was decreased to $110 \pm 5 \mathrm{mmHg}$ 4 days after bilateral adrenalectomy. In the SHR blood pressure was $182 \pm$ $3 \mathrm{mmHg}$, and it gradually decreased to $130 \pm 5 \mathrm{mmHg} 4$ days after the adrenalectomy. The normotensive level of $131 \pm 10 \mathrm{mmHg}$ was maintained to the end of the experiment. On the contrary, blood pressure of medullectomized SHR persisted between 180 and $190 \mathrm{mmHg}$ for 7 days after the operation. At autopsy on the eighth day after removal of the medulla, it was replaced with blood, and there was no indication of the regeneration of medullary cells.

The content of adrenaline and noradrenaline in the adrenals of control NWR were $708 \pm 25$ and $162 \pm 20 \mu \mathrm{g} / \mathrm{Gm}$, respectively. Those in the adrenal medullectomized NWR were only $10 \pm 5$ and $3 \pm 3 \mu \mathrm{g} / \mathrm{Gm}$. In the medullectomized SHR, catecholamines were also greatly reduced from $670 \pm 20$ (adrenaline) and $190 \pm$ (noradrenaline) to $20 \pm 9$ and $2 \pm 5 \mu \mathrm{g} / \mathrm{Gm}$, respectively.

The results demonstrate that the hypertension in SHR persisted by the abscence of the adrenal medulla, but high blood pressure became to normotensive level following adrenalectomy. It is suggested that adrenal cortical activity may contribute to persistence of hypertension in SHR by inducing \footnotetext{
Nagoya.

From the Departments of Medicine and Physiology, School of Medicine, Nagoya City University,
} 
intracellular electrolyte imbalance of cardiovascular muscle, the electrolyte include calcium being important for the regulation of muscular tone in the cardiovascular system. 